\title{
Microscopic Findings Completion Status
}

National Cancer Institute

\section{Source}

National Cancer Institute. Microscopic Findings Completion Status. NCI Thesaurus. Code C117588.

A term used to describe the state or condition of the completeness of the microscopic findings data. 